\title{
Strategi Manajemen Penyiaran Program Karaoke Dangdut (Kadut) pada Radio Suara Medan
}

\section{Management Strategy for Broadcasting Karaoke Dangdut (KADUT) on the Radio Suara Medan}

\author{
Rendy Ilhamsyah Siregar1) *, Yan Hendra' ${ }^{2)}$, Syaiful Novri ${ }^{3)}$ \\ Program Studi Ilmu Komunikasi, Fakultas Ilmu Sosial Dan Politik, Universitas Medan Area, \\ Indonesia
}

\begin{abstract}
Abstrak
Karaoke Dangdut atau yang disebut KAKDUT merupakan sebagai salah satu acara unggulan di Radio Suara Medan merupakan program acara yang mengudara setiap hari Senin sampai Sabtu dengan jadwal siar pukul 13.00-15.00 WIB. Acara yang menyiarkan dan mengajak masyarakat untuk Karaoke Dangdut di radio Suara Medan dan/atau Karaoke melalui on air by phone serta memutarkan lagu-lagu dangdut yang hits. Maka dengan adanya penelitian ini bertujuan untuk mengetahui bagaimana strategi manajemen penyiaran program acara karaoke dangdut. Strategi yang dipakai oleh radio untuk karaoke dangdut menggunakan strategi POAC (Planning, Organizing, Actuating, Controlling). Metode yang digunakan peneliti metode kualitatif, yaitu menjelaskan fenomena dengan mengumpulkan data-data kemudian dianalisa untuk memperoleh suatu kesimpulan. Penelitian ini dilakukan dengan cara observasi dan wawancara mendalam terhadap Manager Radio dan Penyiar.
\end{abstract}

Kata Kunci: Karaoke Dangdut, POAC, Program Unggulan.

\begin{abstract}
Karaoke Dangdut or what is called KAKDUT is one of the featured programs at Radio Suara Medan, an program that airs every Monday to Saturday with a broadcast schedule from 13.00-15.00 WIB. An event that broadcasts and invites the public to Karaoke Dangdut on Suara Medan radio and / or Karaoke via on air by phone as well as playing hits dangdut songs. So with this research aims to find out how the broadcast management strategy of dangdut karaoke programs. The strategy used by radio for dangdut karaoke uses the POAC (Planning, Organizing, Actuating, Controlling) strategy. The method used by researchers is qualitative methods, namely explaining the phenomenon by collecting data and then analyzing it to obtain a conclusion. This research was conducted by means of observation and in-depth interviews with the Radio Manager and Broadcasters.
\end{abstract}

Keywords: Karaoke Dangdut, POAC, Primary Program.

How to Cite: Siregar, R.I. Hendra, Yan. \& Novri, Syaiful. (2020). STRATEGI MANAJEMEN PENYIARAN PROGRAM KARAOKE DANGDUT (KAKDUT) pada RADIO SUARA MEDAN. Jurnal Ilmu Pemerintahan, Administrasi Publik, Ilmu Komunikasi (JIPIKOM), 2(2) 2020: 110-114,

*E-mail: rendyilhamsyahsiregar@gmail.com ISSN 2550-1305 (Online) 


\section{PENDAHULUAN}

Radio merupakan salah satu media penyiaran atau media elektronik Menurut UU Nomor 32 tahun 2002 pasal 1 ayat 2 penyiaran adalah kegiatan menyebarluaskan siaran melalui sarana pemancar atau sarana transmisi di darat, di laut atau di antariksa dengan menggunakan spektrum frekuensi radio melalui udara, kabel atau media lainnya untuk dapat diterima secara serentak dan bersamaan oleh masyarakat dengan perangkat penerima siaran. Mengelola media penyiaran pada dasarnya adalah mengelola manusia. Keberhasilan media penyiaran sejatinya ditopang oleh kreativitas manusia yang merupakan fungsi vital yang dimiliki setiap media penyiaran yaitu teknik, program radio. Dalam rangka menjawab tantangan tersebut diperlukan strategi mengelola radio, Prayudha (2005) menyebutkan:

"Pada saat para pengelola stasiun penyiaran radio hendak merencanakan beroperasi, salah satu faktor yang perlu menjadi kajian khusus adalah cara menetapkan target pendengar". Apalagi dengan masa sekarang ini, kompetisi semakin tinggi target pendengar menjadi prioritas. Oleh karena itu, dalam upaya pencapaian target pendengar tersebut diperlukan "programming".

Programming itu sendiri merupakan sebuah proses mengatur program demi program termasuk penjadwalannya sehingga terbentuk stasiun format dengan tujuan menciptakan image stasiun penyiaran radio. Strategi Manajemen Program Siaran Radio adalah seni, ilmu, teknik, dan proses pengelolaan program siaran radio di tingkat strategi, yaitu tingkat tertinggi yang biasanya disusun oleh Dewan Direksi dan dilaksanakan oleh Direktur Program serta tim eksekutif stasiun radio. Manajemen strategis memberikan arahan menyeluruh untuk pemrograman siaran radio, menyangkut ide, metode, riset, teknologi pemrograman, dan peraturan. Strategi manajemen program siaran radio diperlukan oleh sebuah media radio untuk merencanakan bagaimana agar program yang disiarkan bisa menarik banyak pendengar dan pengiklan (Nurleli, 2017).

Radio Bonita Jaya Suara Medan atau yang lebih dikenal dengan sebutan "Radio Dangdut Medan" berdiri pada tanggal 26 Februari 2000. Persentase format acara yang mencapai $70 \%$ adalah untuk pemutaran musik dan 30\% lagi adalah untuk menebak lagu, budaya, berita, dan iklan sebagai selingan acaranya (informasi dari hasil wawancara dengan seorang personalianya yaitu Bpk Dharma, Maret 2017). Dengan adanya program Karaoke Dangdut ini masyarakat dapat mengenal dan mengetahui program yang banyak diminati masyarakat. Strategi Manajemen penyiaran dalam Program Karaoke Dangdut harus dapat meningkatkan lagi sebagai program keunggulan bagi masyarakat banyak karena selain untuk lebih mendekatkan kepada masyarakat yang sudah lebih dahulu mengenal acara tersebut, juga sekaligus ingin memberitahukan atau menginformasikan kepada masyarakat yang belum mengetahui acara Karaoke Dangdut agar mereka turut mengikuti acara tersebut. Dengan program Karaoke Dangdut itu sendiri merupakan sebuah proses mengatur program demi program termasuk penjadwalannya sehingga terbentuk stasiun format dengan tujuan menciptakan image stasiun penyiaran radio.

Dangdut adalah salah satu ragam seni musik nusantara yang berasal dari seni etnis Melayu, yang didalamnya mengandung unsur musik Arab, India, Melayu. Selain instrumen band biasa (gitar melodi, gitar bas, dan keyboard), instrumen khas dangdut lainnya adalah suling bambu dan dua buah gendang yang dimainakan oleh seorang musisi (mirip tabla dan bongo). Pola ritme gendang yang sarat dengan sinkopasi mengalir terus memberikan warna tersendiri pada musik ini. Istilah dangdut muncul pada tahun 1970-an yang berasal dari onomatopeik bunyi gendang tabla yang menjadi ciri khas musiknya yang menghasilkan bunyi nduut asic. Dangdut merupakan sebuah genre musik modern hasil dari proses akulturasi, yang populeritasnya lebih besar dibandingkan keroncong. Lebih dari itu, dangdut merupakan musik populer yang lebih "murni" dalam pengertianya bahwa dalam evolusinya tidak ditarik oleh media massa yang pertunjukanya ala Indonesia, baik asal-usul maupun penontonya 
menpunyai beberapa gaya yang dapat di indentifikasikan berbeda dengan gaya seni pertunjukan Indonesia pada umumnya.

Dangdut dianggap berasal dari musik melayu, yang dapat ditandai dengan awal penyebutanya sebagai musik irama Melayu, rentak Melayu, Orkes Melayu (OM), irama semenanjung Melayu, dan sejenisnya. Di dalam film-film Melayu, dimasukkan unsur music Melayu yang menjadi dasar seni dangdut. Pada tahun 1960an, ketika Indonesia sedang hangat-hangatnya mengembalikan kepribadian budaya bangsa untuk melawan pengaruh budaya barat, jejak said Effendi yang menyanyikan lagu top hits nya Bunga Seroja dalam film Seroja di ikuti oleh A.Chalik, Husen Bawafie, Hasnah Tahar dan Ellya Alwi Khadam di Jakarta.didalam orkestra, lagu-lagu mereka telah di iringi alat musik seruling, seperangkat drum, serta gendang ronggeng melayu.

Format adalah penyajian program atau musik yang memiliki ciri-ciri tertentu oleh stasiun radio. Menurut Fringle Star-Mc. Cavit dalam Nelia Sihombing mengatakan bahwa seluruh format stasiun radio dapat dikelompokkan manjadi tiga kelompok besar yaitu: format musik (hiburan), format informasi dan format khusus (speciality). Format musik adalah format yang paling banyak digunakan radio dan lebih banyak digemari karena sifatnya yang menghibur. Dari pengamatan penulis, Radio Bonita Jaya Suara Medan digolongkan kedalam format musik (hiburan) dengan menampilkan musik dangdut sebagai program utama siaran musik dengan target pendengar masyarakat kelas menengah kebawah dari semua jenis usia.

\section{METODE PENELITIAN}

Metode penelitian kualitatif adalah metode yang lebih menekankan pada aspek pemahaman secara mendalam terhadap suatu masalah daripada melihat permasalahan untuk penelitian generalisasi. Metode penelitian ini lebih suka menggunakan teknik analisis mendalam (in-depth analysis), yaitu mengkaji masalah secara kasus perkasus karena metodologi kualitatif yakin bahwa sifat suatu masalah satu akan berbeda dengan sifat dari masalah lainnya. Tujuan dari metodologi ini bukan suatu generalisasi tetapi pemahaman secara mendalam terhadap suatu masalah. Penelitian kualitatif berfungsi memberikan kategori substantif dan hipotesis penelitian kualitatif.

Merupakan sumber tempat memperoleh keterangan penelitian. Adapun yang dijadikan sumber sebagai sumber data dalam penelitian ini, adalah Program Director., Staff Program Bagian Ide Kreatif, Penyiar, Produser Eksekutif. Kategori yang dipakai oleh Radio Suara Medan dalam strategi manjemen penyiaran sebagai berikut: Planning Penyiaran, Organizing Penyiaran, Actuating Penyiaran, Controlling Penyiaran. metode yang digunakan dalam penulisan adalah sebagai berikut: Metode Observasi, Metode Dokumentasi, Metode Studi Pustaka. Pengujian kredibilitas data didalam sebuah penelitian sangat berpengaruh terhadap hasil penelitian. Hal ini dilakukan untuk membuktikan apakah hasil penelitian sudah sesuai dengan kondisi dan situasi fakta dan data yang ada di lapangan. Kreadibilitas penelitian kualitatif adalah keberhasilan mencapai maksud mengeksplorasi masalah yang majemuk atau kepercayaan terhadap hasil data penelitian.

\section{HASIL DAN PEMBAHASAN}

Pembahasan dari hasil penelitian di Radio Suara Medan dengan judul "Strategi Manajemen Peneyiaran Program Karaoke Dangdut Pada Radio Suara Medan". Hasil penelitian terhadap 2 Narasumber mengenai strategi manajemen penyiaran terhadap program Karaoke Dangdut. Peneliti mengatakan bahwa Ada cara yang dilakukan Radio Suara Medan 
sebagai strategi POAC (Planning, Organizing, Actuating and Controlling) yang dilakukan untuk tercapainya visi serta misi adalah dengan menganalisa program/masalah dan melakukan evaluasi di program karoke dangdut (Terry,2012). Selain itu peneliti mengungkapkan strategi POAC dari hasil penelitian, peneliti juga mengatakan bahwa Manajemen Media Penyiaran Kesuksesan perusahaan penyiaran Radio Suara Medan ditopang dari bagaimana kualitas sumber daya manusia yang bekerja pada ketiga bidang yang disampaikan Morissan di atas. Meski begitu, kualitas dari sumber daya manusia saja belum cukup. Semua itu harus disertai juga dengan kemampuan pimpinan perusahaan penyiaran yang mengelola keryawan yang bergabung dengan perusahaan tersebut. Karena inilah manajemen yang baik sangat diperlukan dalam sebuah perusahaan penyiaran.

Strategi manajemen POAC di dalam media penyiaran memiliki empat fungsi dasarnya, sehingga untuk menjalankan strategi dalam meningkatkan kualitas sumber daya manusia, khususnya di program karoke dangdut, manajemen harus memiliki empat fungsi dasar tersebut. Dengan pemaparan sebagai berikut: Perencanaan adalah menyiapkan rencana dan strategi yang akan dikerahkan guna mencapai tujuan perusahaan penyiaran. Dalam tahapan ini harus sudah tahu tentang apa yang harus dilakukan, kapan, bagaimana dan siapa yang akan menjalankan rencana tersebut. Radio Suara Medan memiliki Visi dan Misi perusahaan yang menjadi acuan pembuatan sebuah rencana perusahaan. Visi sendiri adalah cita-cita atau harapan dari suara medan untuk mewujudkan sebuah keadaan di masa depan. Sementara Misi adalah tujuan yang akan diraih dengan melakukan pekerjaan yang memang harus dilakukan.

Pengorganisasian, Pada umumnya, struktur organisasi stasiun penyiaran tidak memiliki aturan yang tetap. Bentuk stasiun penyiaran berbeda-beda antara satu menajemen dengan manajemen yang lain. Tanggung jawab dalam menjalankan sebuah radio terbagi menjadi dua kategori, yaitu manajemen penyiaran dan pelaksanaan operasional penyiaran. Struktur organisasi di Radio Suara Medan lebih sederhana. Ini juga dilihat dari pembagian kerjanya yang tidak terlalu rumit. Secara umum, organisasi penyiaran di suara medan terdiri dari paling atas adalah direktur utama, dan manajer stasiun. Dibawahnya terdiri dari manajer level menengah seperti traffic dan marketing. Traffic membawahi produser, penyiar dan reporter. Sementara marketing membawahi tenaga sales.

Pengarahan dan memberika, Pengaruh Mengarahkan dan memberikan pengaruh memiliki tujuan agar merangsang antusiasme karyawan dalam menjalankan tanggung jawab kerja secara efektif. Fungsi memengaruhi atau mengarahkan fokus pada stimulasi karyawan dalam melaksanakan tanggung jawab yang dimiliki secara antusias dan efektif. Kemudian, pengawasan, Di Radio Suara Medan, pengawasan dilakukan berdasarkan kinerja karyawan yang bisa diukur agar penilaian berjalan secara efektif. Sebagai contoh, tingkat kepuasan pendengar radio yang ditentukan oleh sedekat apa penyiar dengan pendengar. Bagaimana cara menyampaikan informasi secara cerdas, serta kedekatan pada saat melakukan visitasi atau menyapa pendengar. Walaupun diucapkan untuk umum, namun bagaimana pendengar tersebut mampu menerima secara personal dari penyiar.

Selain itu peneliti, dalam melakukan evaluasi, manajemen Radio Suara Medan menggunakan analisa SWOT. Dari analisis SWOT tersebut dapat dikembangkan dan ditarik antara hubungan dari masing-masing analisis. Antara Strenghts dan Opportunities, atau Weakness dan Threats, dan hubungan antar masing-masing analisis adalah sebagai berikut: 
Strengths dan Opportunities strategi, yaitu kekuatan dari sumber daya yang dimiliki Suara Medan yaitu memiliki penyiar yang kompeten dan berwawasan tinggi mampu melebarkan peluang dari progam acara Karaoke Dangdut yang dimiliki Radio Suara Medan namun tidak dimiliki oleh radio lain, seperti Karaoke Dangdut yang di update setiap 3 jam sekali. Hal ini membuka peluang untuk meraih pendengar dari kalangan remaja sampai orang tua.

Weakness dan Opportunities strategi, yaitu kelemahan yang dimiliki Radio Suara Medan adalah Karaoke Dangdut yang dilakukan secara langsung di radio, sehingga tingkat kesalahan dalam membaca skrip masih tinggi, namun hal ini dapat diatasi dengan peluang yang dimiliki oleh Radio Suara Medan tentang program acara yang dibutuhkan oleh pendengar. Strengths dan Threats strategi, yaitu untuk menghindari adanya persaingan bisnis yang sejenis, yaitu dengan radio lain, maka Radio Suara Medan menyasar segmen pebisnis dengan terus mengasah kemampuan penyiarnya untuk mengerti apa yang dibutuhkan oleh pendengar. Weakness dan Threats strategi, yaitu radio suara medan harus membuat sebuah strategi sendiri, untuk mengatasi kelemahan yang dimiliki untuk mengatasi ancaman di luar sana yang memiliki acara atau program Karaoke Dangdut yang lebih bagus. Untuk itu Radio Suara Medan terus melakukan evaluasi siaran dan program Karaoke Dangdut yang rutin dilakukan tiap hari

\section{SIMPULAN}

Dari penelitian ini dapat disimpulkan bahwa Radio Jaya Bonita Suara Medan pada program acara Karaoke Dangdut mempunyai strategi manajemen penyiaran yaitu strategi manajemen POAC ( Planning, Organizing, Actuating and Controlling ). Strategi manajemen POAC sangat penting didalam dunia penyiaran. Penggunaan strategi POAC pada manajemen penyiaran sangat di utamakan di program karoke dangdut sebagai karoke unggulan di Radio Jaya Bonita Suara Medan.

\section{DAFTAR PUSTAKA}

Cangara, Hafied. 2011. Pengantar Ilmu Komunikasi. Jakarta : RajaGrafindo Persada

Cangara, Hafied. 2014. Perencanaan \& Strategi komunikasi. Jakarta : RajaGrafindo Persada

Liliweri, Alo. 2014. Sosiologi \& Komunikasi Organisasi. Jakarta : Bumi Aksara

Mabruri, Anton. 2013. Manajemen Produksi Program TV. Jakarta : Grasindo

Nurleli, (2017), Manajemen Pemberitaan Kriminal pada Program Tangkis di iNews TV dalam memenuhi Kepuasan Pemirsa, Jurnal Simbolika: Research and Learning in Comunication Study, 3 (2): 78-86.

Prayudha, Harley, 2005, Radio Suatu Pengantar untuk Wacana dan Praktik Penyiaran, Malang: Bayumedia Publishing

Ruliana, Poppy. 2016. Komunikasi Organisasi Teori \& Studi Kasus. Jakarta : RajaGrafindo Persada.

Terry, G. R. (2012). Principle Of Management: Irwin Series in Industrial Engineering and Management. Literary Licensing, LLC 